\title{
Some new perspectives on the inter-country analysis of the world production system
}

\author{
Yuji Aruka ${ }^{1}$
}

Published online: 24 October 2017

(C) The Author(s) 2017. This article is an open access publication

\begin{abstract}
When production theory is discussed in the traditional economic custom, somehow, either intermediate goods or price determination is often not examined precisely. The prices are usually fixed, while scarcity of resources is exceptionally attached importance. The efficiency of production is consequently forced to be adapted to a given price system of goods. However, this kind of restrictive treatments of production came up against several difficulties when the theory of international trade is argued in terms of Ricardo and Heckscher-Ohlin, i.e., comparative cost theory. The object of international transactions may not be limited to such resources as regulations are often imposed. It is rather important to trade not only among the different intermediate goods but also even among the same kinds of intermediate goods empirically shown in Ikeda et al. (RIETI Discuss Pap Ser 16(E26):1-35, 2016). Thus, the introduction of intermediate goods for production is indispensable to develop the theory of international trade. Even in the 21 st century, however, economists were still frustrated to escape from a special two country-two commodity case. Fortunately, by remarking geometry, Shiozawa (Evolut Inst Econ Rev 3(2):141-187, 2007; Evolut Inst Econ Rev 12(1):177-212, 2016; A new construction of Ricardian theory of international values: analytical and historical approach, pp 3-73. Springer, Berlin, 2017) has been successful to establish a price determination in a more general case of three country-three commodity. In Shiozawa (Evolut Inst Econ Rev 12(1):177-212, 2016), he smartly employed a subtropical geometry to examine a general case of international trade, i.e., three country-three commodity case. Behind his idea, there is the idea of Minkowski space of production, in particular, zonotope. This approach will give a different view of production set, and possibly suggest a further generalization more than three of the number of country and commodity. First of all, this article gives a brief look
\end{abstract}

Yuji Aruka

aruka@tamacc.chuo-u.ac.jp

1 Chuo University, Hachioji-city 192-0393, Japan 
of the new essence of Shiozawa's theory, and then gives by some numerical simulation a new characterization of international trade in line with Shiozawa's theory. Furthermore, this article examines the effect of the introduction of free international trade. The introduction of the optimization rule to international trade results in drastic changes in network structures. Finally, the link with the network analysis and econophysics will be argued.

Keywords Sub-tropical geometry · International trade · Network structure · Deregulation · Intermediate commodity

JEL Classification $\mathrm{F} 1 \cdot \mathrm{C} 6 \cdot \mathrm{D} 5 \cdot \mathrm{B} 12 \cdot \mathrm{L} 11$

\section{An introductory review on the international trade}

\subsection{An integration of two production systems through specialization}

It is well known that an integration of any two production systems $\{A, B\}$ will bring some more efficient production as a whole than a simple sum of the production amounts over the two independent systems. For simplicity, we suppose that each system can produce two goods $\{x, y\}$ common to the two systems. We then give a simple example. We have two states of each production system where any system can specialize her production to some particular good of any two goods. Thus, we may have a state with specialization and a state without specialization to some particular good.

It is shown that specialization can increase the total production of $A$ and $B$ for both goods $x$ and $y$. An efficient total production can only be achieved if either $A$ or $B$ specializes in producing the good in which they have a comparative advantage. We assume that a production possibility frontier is linear. In comparison between given two systems, a comparative advantage of any system will be then revealed as for the production of one of two goods. For instance, the system $A$ has a comparative advantage in the production of $y$. The system $B$ has a comparative advantage in the production of $y$. If it is the case, the production possibilities frontier of the systems $A$ and $B$ will be then depicted in Fig. 1. Thus, the frontiers of both countries have their maximum production on each good, respectively. We denote the system $A$ 's maximum capacity on good $x$ by $X_{\max A}$, on good $y$ by $y_{\max A}$, for instance. The same notations are applied to $X_{\max B}$, on $\operatorname{good} y$ by $y_{\max B}$ for the system $B$.

Now, we employ a numerical example as shown in Table 1.

In our instance shown by Table 1, there are two modes of production: independent mode and integrative mode, i.e., the mode "without specialization" and the mode "with specialization."

In an integrative mode, $A$ can produce 50 units of $X$, while $B$ can produce 100 units of $Y$. Here, $x \in X$ and $y \in Y$. On the other hand, either $A$ or $B$ can only produce less than her maximum amount which they can specialize their production. We set $\alpha=\frac{Y_{\max } B}{X_{\max A}}$. Hence, it depends on the ratio $\alpha$ whether $A$ or $B$ should specialize. In our 


\begin{tabular}{|c|c|c|c|c|c|c|c|}
\hline & \multicolumn{3}{|c|}{ without specialization } & \multicolumn{3}{|c|}{ with specialization } & increase \\
\hline & $\bar{A}$ & $\bar{B}$ & $\mathrm{~A}+\mathrm{B}$ & $\bar{A}$ & B & $\mathrm{A}+\mathrm{B}$ & $\mathrm{A}+\mathrm{B}$ \\
\hline units of $X$ & 15.0 & $\overline{7.5}$ & 22.5 & 20.0 & 4.0 & 24.0 & 1.5 \\
\hline units of $Y$ & $\frac{5.0}{2.0}$ & 30.0 & 32.5 & 0.0 & 34.7 & 34.7 & 2.2 \\
\hline
\end{tabular}
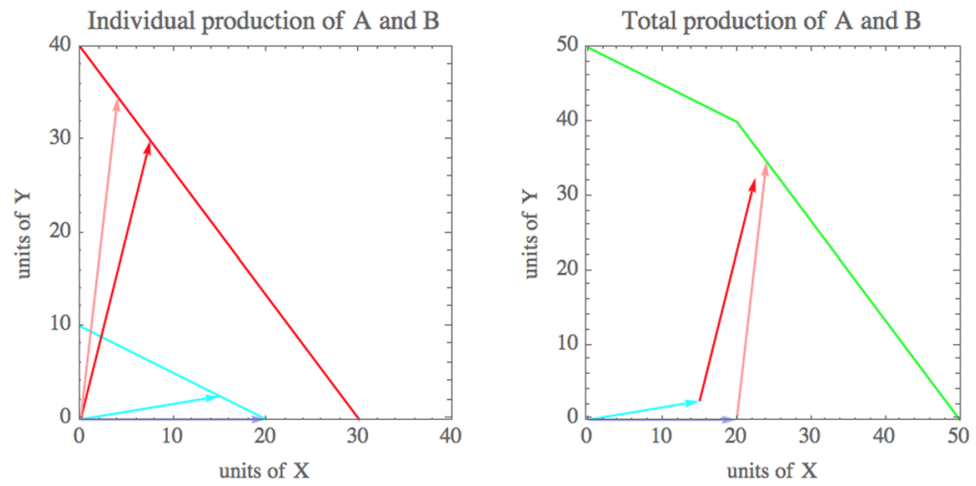

\begin{tabular}{lll|}
$\longrightarrow$ & production possibilities frontier of $\mathrm{A}$ & production possibilities frontier of B \\
production of A with specialization & & production of B with specialization \\
production of A without specialization & & production of B without specialization \\
joint production possibilities frontier of A and B &
\end{tabular}

Fig. 1 Activity analysis of integration of two independent production systems through specialization (drawn by Brechtefeld 2012)

Table 1 Numerical instance

\begin{tabular}{llllll}
\hline System & \multicolumn{2}{l}{ Independent } & & \multicolumn{2}{l}{ Integration } \\
\cline { 2 - 3 } \cline { 5 - 6 } Commodity & $A$ & & & $A$ & \multicolumn{1}{l}{$B$} \\
\hline$x$ & 15 & 7.5 & & 20 & 4 \\
$y$ & 2.5 & 30 & & 0 & 34.7 \\
\hline
\end{tabular}

example, if $\frac{Y}{X} \geq \alpha, A$ must specialize in the production of $X$, and vice versa. We may then allow an intermediate case that $A$ can produce both goods but $B$ can specialize to produce $Y$. This illustrates how a comparative advantage in integration for specialization can occur given some independent systems. The result is represented by the activity analysis of Fig. 1. In Fig. 1, the specialization to a particular commodity due to its comparative advantage in the system $A$ is demonstrated. However, this kind of specialization does not refer to and/or specify at all how the outputs will be exchanged among the systems. The transactions among the systems should be complex if the outputs were also used as the intermediate goods for production. This is the reason why the classical international trade theory was not updated until Shiozawa $(2007,2016)$ has mathematically innovated by the use of sub-tropical geometry. 
In the following, we will argue an integration through international trades. Taking into account international trades, however, the effect of integration of independent systems must be more complex. The effect could not be confirmed by a simple comparison of comparative advantage in terms of real productivity among the independent systems. We will require a more roundabout reasoning on the idea of comparative advantage.

\subsection{Production set in the Minkowski space}

We describe the ex post technology of a production unit as follows:

$$
\left(a_{1}, \ldots, a_{l}, a_{l+1}\right) \in \mathfrak{R} .
$$

We then observe the production set $Y$. Given a family $\left\{a_{i}\right\}_{i \in N}$, the short-run total production set is written in the following manner:

$$
Y=\sum_{i \in N}\left[0, a_{i}\right]
$$

In economics, there were few to discuss production in context of zonotope. Zonotope is one of the Minkowski space family. A convex polygon is a zonotope if and only if all its two-dimensional faces have a center of symmetry. By the use of this idea, we can observe all possible combinations for production without resort to any restriction of efficiency.

Hildenbrand (1981) defines the short-run total production set associated with them as the zonotope. The short-run production possibilities of an industry with $N$ units at a given time is a finite family of vectors $\left\{a_{i}\right\}_{1 \leq i \leq N}$ of production activities:

$$
Y=\left\{y \in \mathfrak{R}_{+}^{l+1} \mid y=\sum_{i=1}^{N} \phi_{i} a_{i}, 0<\phi_{i}<1\right\} .
$$

According to Hildenbrand, this idea differs from the traditional production function. We define the projection of $Y$ on the input space $\mathfrak{R}_{+}^{l}$ :

$$
D=\left\{V \in \mathfrak{R}_{+}^{l} \mid(V, X) \in Y \quad \text { for some } X \in \mathfrak{R}_{+}\right\} .
$$

It then hods the traditional production function:

$$
F(V)=\max \left\{X \in \mathfrak{R}_{+} \mid(V, X) \in Y\right\} .
$$

The operator max in the above has excluded the possibilities of "certain institutional barriers to factor mobility in aggregating the individual production sets" (Hildenbrand 1981, 1097).

In general, the ex post technology of a production unit is a vector i.e., a production activity $a$ that produces, during the current period, $a_{l+1}$ units of output by means of $\left(a_{1}, \ldots, a_{l}\right)$ units of input. The size of the firm is the length of vector $a$, i.e., a multi-dimensional extension of the usual measure of firm size (Fig. 2).

Given $Y=\left(a_{1}, \ldots, a_{l}\right)$, a set of generators for $n$, the zonotope $Y$ is the convex hull of all vectors of the form $a$; that is, $(Y)$ is the Minkowski sum of all segments $\left[0, a_{i}\right]$, 


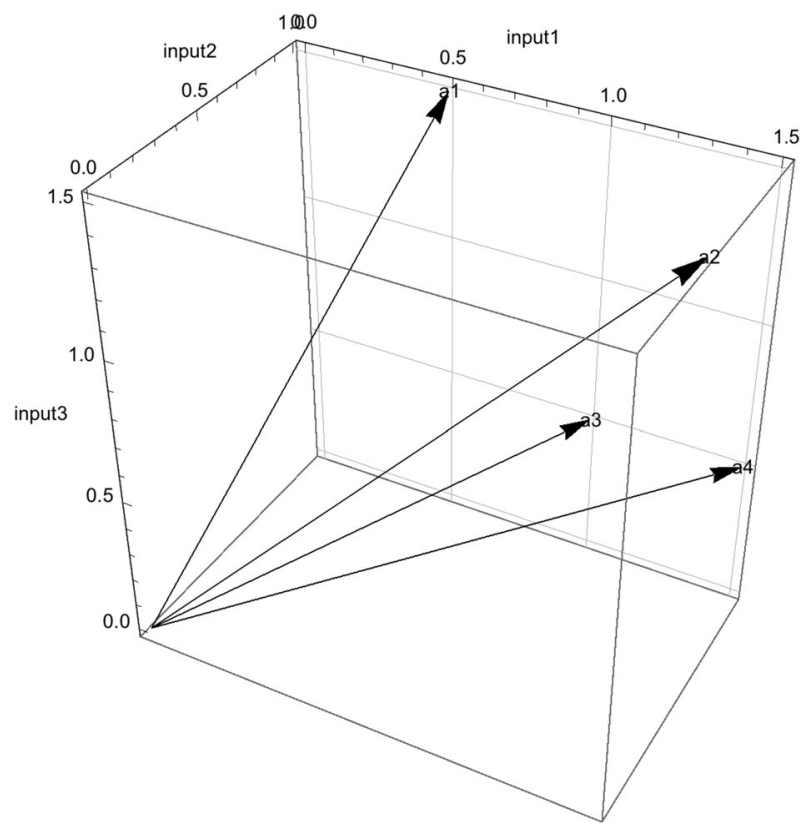

Fig. 2 Activity analysis of integration of two independent production systems through specialization

where $a \in Y$, i.e., $\sum_{a_{i} \in Y} a_{i}$. Also $Z(Y)$ is the shadow of the $r$-dimensional cube $[0,1]^{r}$ via the projection. ${ }^{1}$ It is noted that the application of zonotope to production set was recently achieved by Dosi et al. (2016). They employed the volume of zonotope $Y$ in $\mathfrak{R}:$

$$
\operatorname{Vol}(Y)=: \sum_{1 \leq i_{1} \leq i_{2} \cdots \leq i_{l} \leq N}\left|\Delta i_{1}, \ldots, i_{l}\right| .
$$

Here, $\left|\Delta i_{1}, \ldots, i_{l}\right|$ is the module of the determinant. This kind of discussion will suggest a new growth/innovation theory of production. This approach may be classified into the complex adaptive system. This matter may be referred by the author elsewhere (Fig. 3).

\subsection{Shiozawa's innovative use of zonohedron}

Another more sophisticated/innovativeinstance has recently been shown by Shiozawa (2016) when he argued the international production system of 2 country-3 goods case (Shiozawa 2016, 13: Some New Topics in International Trade Theory). Here, he dealt with intermediate goods in the international trade. See Fig. 4. Shiozawa's diagram (Shiozawa's polygon) is interpreted as Minkowski sum of any two triangles (any two countries A and B). First, each triangle is composed

\footnotetext{
${ }^{1}$ Under the projection $\left.\left(t_{1}, \ldots, t_{r}\right) \mapsto \sum_{i=1}^{r} t_{i} a_{i}\right)$, the shadow of the $r$-dimensional cube $[0,1]^{r}$ is $Z(Y)$.
} 


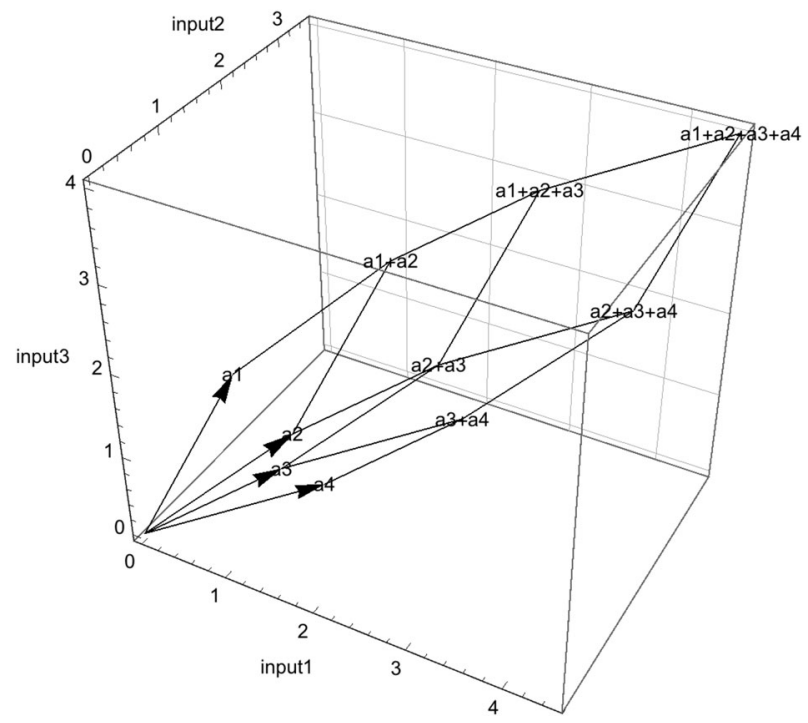

Fig. 3 The zonohedron, given the original four activities $\left\{a_{1}, a_{2}, a_{3}, a_{4}\right\}: \sum_{i=1}^{4}\left[0, a_{i}\right] \subset R^{3}$

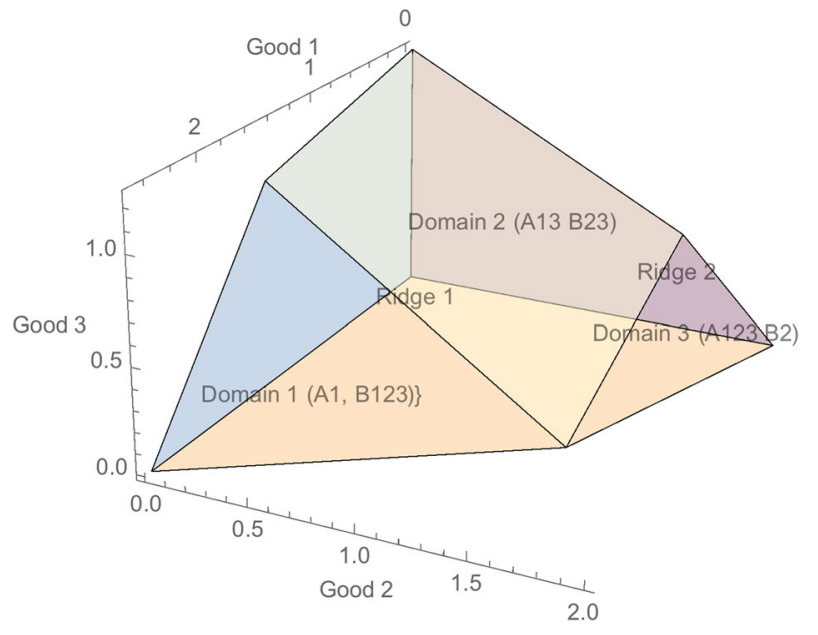

Fig. 4 Shiozawa's diagram

by the commodities space each country separately. However, the composition of two triangles will generate a zonohedron of many facets.

In the following, we will see the double observations how the countries and the commodities are mutually interacted. In other words, a Minkowski sum of any 2 systems will reveal some complex relationships newly generated by the international trade between two countries. This formation is easily shown graphically in Fig. 5. 


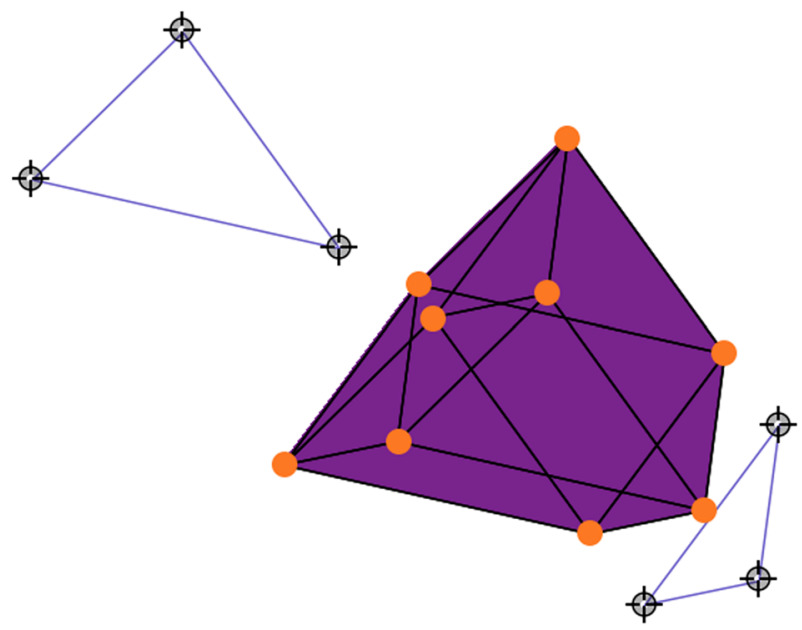

Fig. 5 Minkowski sum of any two triangles

\section{Ricardian economy with international trade}

A Ricardian trade economy, or Ricardian economy, is an economy with $M$ countries and $N$ kinds of commodities, where $M$ and $N$ are positive integers. The usual convention $[M]=1, \ldots, M$ and $[N]=1, \ldots, N$ is used. The economy is given a set of production processes or production techniques, expressed by a rectangular matrix $A$ with $M$ rows and $N$ columns. An entry $a_{i j}$ of A denotes the labour input coefficient for the production technique in country $i$ producing commodity $j$. Thus, $a_{i j}$ 's of labour is required to produce s units of commodity $j$ in country $i$. Each country has a fixed labour force $q_{i}$. This is the maximum quantity of labour available for production in a country. $E$ comprises the set $\{A, q\}$, where $A$ is a set of $M \times N$ positive numbers $a_{i j}$ (i.e., $A=\left[a_{i j}\right]$ and the vector $q$ is a set of $M$ positive numbers $q_{i}$. Thus, a Ricardian economy is simply the couple $\{A, q\}$.

No body has successfully proved the existence proof in its general case of $M$ countries and $N$ kinds of commodities with intermediate inputs. Jones (1961) only gave a sufficiency proof in the special case of $M=N$. However, the number of commodities is actually far bigger than the number of countries. We were keen to generalize Ricardian trade theory. A general case must contain a production of commodities by means of commodities. In this point of view, Yoshinori Shiozawa was the first scholar who successfully proved a general case of Ricardian trade theory in Shiozawa (2007). Here, he employed barycentric coordinates for his proof.

\subsection{Shiozawa's Ricardian international trade theory of sub-tropical form}

$$
w=p \otimes \max B .
$$

First of all, Shiozawa's new proof (Shiozawa 2016) employs the max-times semiring. Every country has an industry in which employers can pay maximal wage rate. 
Let $B$ to be a matrix in which the $(j, i)$ element is $1 / a_{i j}$. If the equation holds, every country $i$ has a commodity $j=j(i)$, such that

$$
w_{i}=p_{j} / a_{i j} \quad \text { and } \quad p_{j} / a_{i j} \geq p_{i} / a_{i k} \quad \text { for } \forall k \in[N] .
$$

This means that every country has an industry in which employers can pay the maximal wage rate. This has been equivalent to the same effects as cost minimization according to Fujimoto's empirical observations of innovation processes of the manufacturing industries (Fujimoto 2007; Fujimoto and Shiozawa 2012). Hence, he confirmed the conjugacy between wage rates and prices. In the event, a list of major conjugate relations in Ricardian economy has been established.

Shiozawa (2016), second, confirmed in the Ricardian economy that the subtropical hyperplane arrangement with full commodity apexes (in case of min-times semi-ring) and with full country apexes (in case of max-times semi-ring) could determine the range of wage rate vectors and price vectors in a self-replacing steady state. Here, Shiozawa regarded the competitive type at a point as spanning, namely, sharing and covering. Therefore, we get the diagrams of spanning core in commodity simplex and spanning core of country simplex. In this elegant arrangement, Shiozawa formulated the world production set in terms of Minkowski sum. This formulation is also innovative for mathematical economies. It is noted that Fig. 4 is driven by Fig. 5 by incorporating the above major conjugate relations.

\subsection{The application of hyperplanes of tropical geometry to the international trade}

Leaving a rigorous proof given by Shiozawa (2017) in Shiozawa et al. (2017), we can easily summarize how the goods and countries generate a complex network structure. In the following, by the use of simplex geometry, we first depict that domains in which each country has cost advantage. We employ this to embed relative prices into this simplex to establish the price simplex of the world production system diagrammatically. We then incorporate the wage simplex into the price simplex to prove "commodity's cost advantage" in countries. In this procedure, we finally find competitive types of country domains in a superposition of the price simplex and the wage simplex.

To develop our idea, we have two ways to express the state of transactions between commodities and countries: commodity-wise notation and country-wise notation. In this illustration, we will employ the latter (Tables 2, 3, 4).

Table 2 Commodity-wise view

\begin{tabular}{lll}
\hline Commodity 1 & Commodity 2 & Commodity 3 \\
$\downarrow$ & $\downarrow$ & $\downarrow$ \\
Country 2,3 & Country 2 & Country 2 \\
\hline
\end{tabular}


Table 3 Country-wise view

\begin{tabular}{lll}
\hline Country 1 & Country 2 & Country 3 \\
$\downarrow$ & $\downarrow$ & $\downarrow$ \\
$\phi$ & Commodity $1,2,3$ & Commodity 2 \\
\hline
\end{tabular}

Table 4 Selection of cost advantage allocation

\begin{tabular}{lll}
\hline Country 1 & Country 2 & Country 3 \\
$\downarrow$ & $\downarrow$ & $\downarrow$ \\
Commodity 2 & Commodity 3 & Commodity 1 \\
\hline
\end{tabular}

Fig. 6 Cost advantages in the country-wise notation

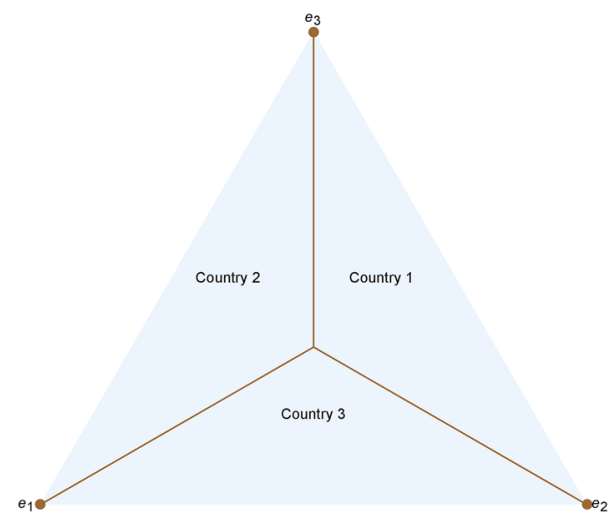

We then allocate the cost advantage of any commodity to any country. We give the next selection of cost advantage for our argument shown in Fig. 6.

The apex of a tetrahedron is degenerated/flattened on a plane. Thus, $V$ is called the apex of commodity space represented by a two-dimensional triangle. We argue the cost advantage when the wage vector $w=\left(w_{1}, w_{2}, w_{3}\right)$ is given in the triangle $V^{1} e_{1} e_{2}$. The cost of production for commodity 1 is then the lowest in country 3 . As the wage vector changes to move to $V^{1} e_{2} e_{3}$, country 1 has the lowest cost of commodity 1 . If the wage vector is found in $V^{1} e_{3} e_{1}$, country 2 has the lowest cost of commodity 1 . Similarly, as in commodity 1 , we can also argue the cost advantages for commodity 2 as well as commodity 3. Therefore, as shown in Fig. 7, we have three apexes such as $V^{1}, V^{2}, V^{3}$, and 10 domains in the triangle, which correspond to the different types of cost advantages, i.e., the different competitive types.

It is noted that $(1,2,1)$ means commodity 1 has the lowest cost in country 1 , commodity 2 has the lowest cost in country 2 , and so on.

We take the set of production coefficients of commodity 1 among 3 countries as $a_{11}, a_{21}, a_{31}$. Using a scalar $c$, we normalize $v_{i}$ by letting 
Fig. 7 There are ten domains in the triangle corresponding to the different types of cost advantages

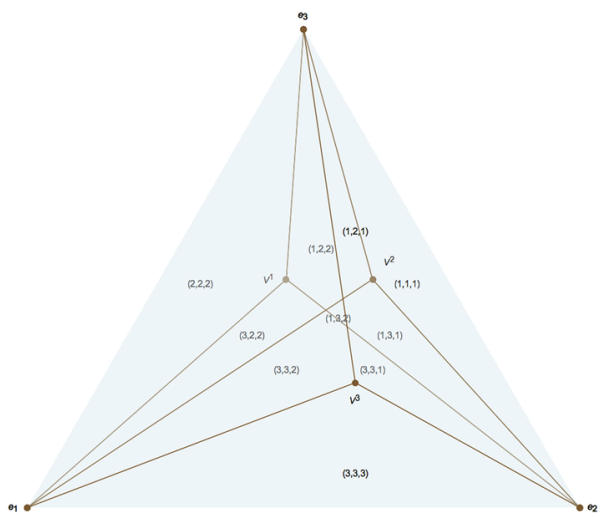

$$
v_{1}=\frac{c}{a_{11}}, \quad v_{2}=\frac{c}{a_{21}}, \quad v_{3}=\frac{c}{a_{31}} .
$$

It then holds

$$
\begin{gathered}
v_{1}+v_{2}+v_{3}=1 \\
c=\frac{1}{a_{11}}+\frac{1}{a_{21}}+\frac{1}{a_{31}} .
\end{gathered}
$$

Figure 8 can establish the comparative costs, by focusing on $w 1$ and $v 3$ on the line $e^{2} e^{3}$. It then follows the next relationships:

$$
\left.\begin{array}{rl}
w_{2}: w_{3} & >v_{2}: v_{3} \\
v_{2}: v_{3} & =\frac{1}{a_{21}}: \frac{1}{a_{31}} \\
w_{2}: w_{3} & >a_{31}: a_{21}
\end{array}\right\} w_{2} a_{21}>w_{3} a_{31} .
$$

If we focus on the line $e^{3} e^{1}$, Fig. 9 can confirm the next:

Fig. 8 Comparison of cost advantages between Country 2 and Country 3 given $V^{1}$ or given that the lowest cost is the commodity 1

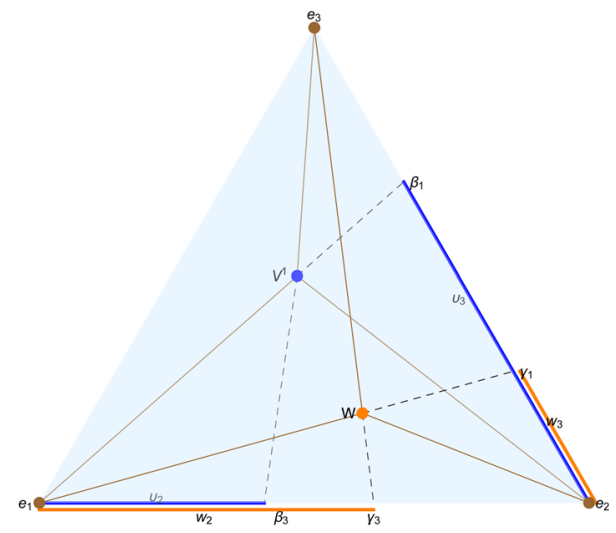


Fig. 9 Comparison of cost advantages between Country 1 and Country 3 , given $V^{1}$ or given that the lowest cost is the commodity 1

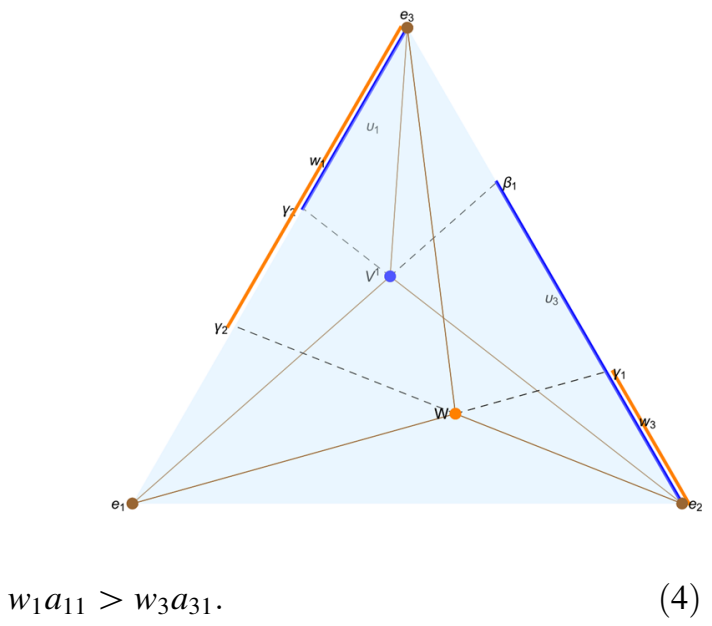

Hence, it is verified that the cost of production for commodity 1 is the lowest in country 3 . As stated in the above, the cost advantages for other commodities than commodity 1 will be confirmed. Therefore, as shown in Fig. 10, that the competitive points will be established at the intersections of $e_{1} v_{2}$ and $e_{2} v_{1}$ and $e_{3} v_{3}$.

\section{A verification of Shiozawa's international trade theory by simulation}

In the first section, when we argued a comparative advantage of an integration of any two independent systems, we noticed that the effects of international trade would give rise to much more complex interactions. Shiozawa (2016) successfully found that this kind of interactions was revealed by some new mathematical transformation like sub-tropical geometry. In short, the essence is no other than wage-price variations among countries through international trades. Needless to say, there is a big difference between a simple comparative advantage of productivity of commodities and the cost advantages between the relationship of commodities and

Fig. 10 Existence of the competitive points

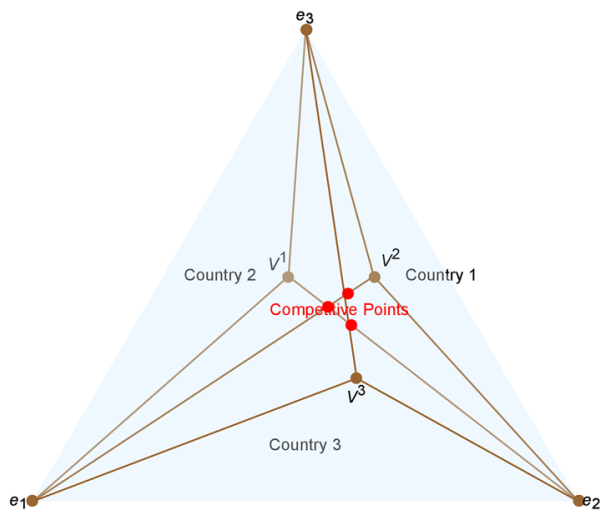


countries. Moreover, we also observed that an idea of comparative advantage would no longer bring any pure specialization of production each country. As an empirical test showed that there may occur an internationally bilateral transaction on the same commodities between any two countries. This must invalidate the old justification of international trade by specialization of production each country, as Shiozawa (2007, 2016) mathematically showed. Thus, we finally verify an occurrence of transaction of the same commodity between countries and some associated meanings of the network order of production. We will achieve this verification by the country-based simulation.

In the following, we employ the idea of multiregional input-output model mainly given by Raa (2006). Raa applied the make minus use tables to formulate a new type of input-output model. Needless to say, the net make less use tables based on the input-output table inherit some restrictions the I/O table by itself retains. The variables appearing in this table are limited to flow variables for a year basis. In our case, there is the sole factor of production, i.e., labour. This assumption rather reveals the main point on which Shiozawa $(2007,2016)$ focused. We also note that the I/O table always deals with commodities as intermediate goods. Thus, we can verify the international trade equilibrium where intermediate goods are imported or exported. According to Nettleton (2011),

the model is quite sophisticated in implementing tableau networked production functions across multiple industries in multiple countries, all interconnected by trade, settled simultaneously in volume and price through linear programming.

Nettleton, moreover, has given a new insight to randomize the net make less use tables. We show the case of three commodities and three countries randomly generated, for instance.

Nettleton regarded this inter-regional production system as one of before deregulation. "Deregulation" means the free international trade. Thus "before deregulation" will suggest a state which cannot move entirely to the free trade for some reason (Table 5).

As for the remaining countries in this inter-regional system Country 2 and 3, it then follows the result of the before deregulation. We first show the state transition of Country 2 (Table 6).

We finally show the state transition of Country 3 (Table 7).

\subsection{The make minus use table and the network diagram}

To argue the input-output system, we need to notice the several versions of the input-output system so far discussed previously. The statistical bureau often announces the input-output tables where the input coefficient is defined as an input amount required to produce a unit of the commodity. On the contrary, the make minus use tables focuses on the net output structure of the production system as well as the inter-regional system. The entry in the table indicates a net output if it is positive, otherwise a net input. As shown in the tables, the matrix of net output and 


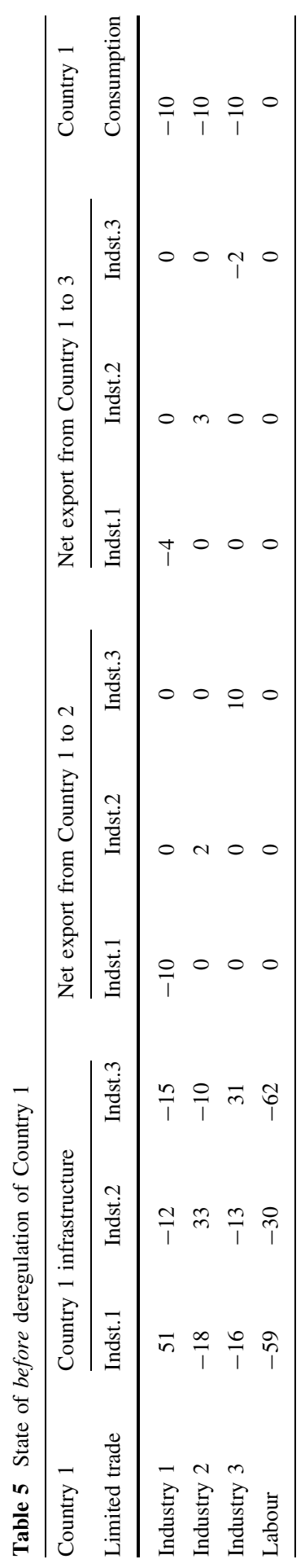




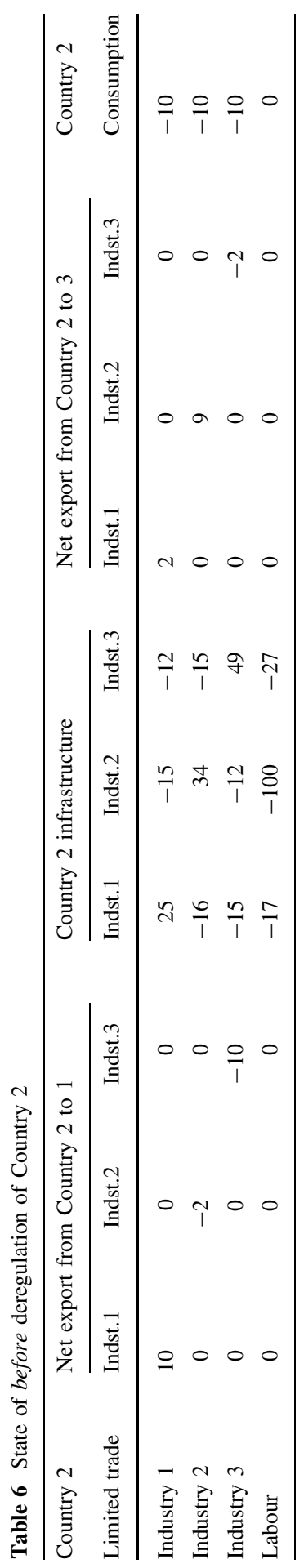




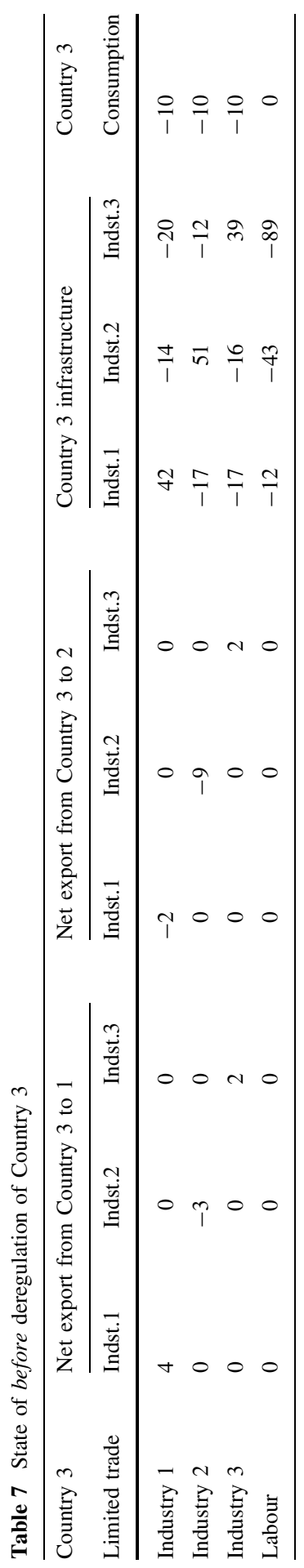


input will not be an adjacency matrix. It will be rather a weighted adjacency matrix. We then examine the next theorem.

\section{Kirchhoff's theorem for directed multigraphs}

Kirchhoff's theorem can be modified to count the number of oriented spanning trees in directed multigraphs. The matrix $\mathrm{Q}$ is constructed as follows:

1. The entry $q_{i j}$ for distinct $i$ and $j$ equals $-m$, where $m$ is the number of edges from $i$ to $j$;

2. The entry $q_{i i}$ equals the in-degree of $i$ minus the number of loops at $i$. The number of oriented spanning trees rooted at a vertex $i$ is the determinant of the matrix gotten by removing the $i_{t h}$ row and column of $Q$.

We focus on the number of oriented spanning trees rooted at a vertex $i$ in our tables. According to Kirchhoff theorem on the adjacency matrix, usually, the off-diagonals of the matrix are -1 . However, we note that our table are not an adjacency matrix but rather a weighted adjacency matrix. The make minus use table is fitted to the definition of weighted Kirchhoff matrix. Thus, we apply the weighted Kirchhoff matrix to our table. ${ }^{2}$ Incidentally, it may be useful to depict a directed network structure of the make minus use tables by the directed graph if the table is asymmetrical. $^{3}$

In our modeling, the produced goods are all allowed to be utilized as the intermediate goods for the self and the production of others. Thus it follows to apply the definition of Kirchhoff entries to the net input/output. Let the entry of net input or net output of good $j$ in the productive sector (process) $i$ be $a_{i j}$, and the exogenous final consumption in the sector $j$ be $c_{j}$ (Fig. 11).

Hence, we show the directed network structure of the make minus use table of Table 5 by the use of Kirchhoff diagram. Here, the number of directed arrows indicates the size of net variables:

$$
\begin{aligned}
& \text { objective } c=(0,0,0,0,-1,0,0,0,0,0,-1,0) \\
& \text { objective function }=\sum_{i}^{12} c_{j} y_{i j} .
\end{aligned}
$$

\subsection{The traditional view of the landscape of the production system}

Now, first of all, we deal with the quantity system of supply and demand. The production system of country $k$ is then represented each country as follows:

Here, $m_{i j}$ is the import coefficient of good $j$ in the productive process $i . z_{i j}$ is the export coefficient of good $j . m_{i j}-z_{i j}$ will be the net export coefficient.

\footnotetext{
${ }^{2}$ The function titled "KirchhoffGraph" of Mathematica is quite helpful to depict the strength of the oriented spanning trees. See, for example, "Weighted Kirchhoff Matrix?" (https://mathematica. stackexchange.com/questions/23122/weighted-kirchhoff-matrix).

${ }^{3}$ See Wikipedia (2017), Wolfram Language and System Documentation Center (2015), and Maurer (1976).
} 
Fig. 11 Table 5 shows that Industry 3 provides Industry 1 with net input of 3 in Country 1. The directed arrow from Industry 3 to Industry 1 consists of 3 lines in Kirchhoff diagram

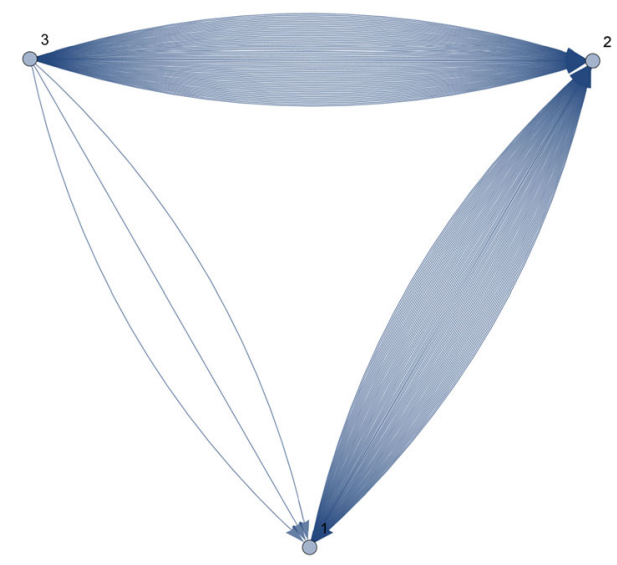

$$
\begin{aligned}
& w^{[k]} l_{i}^{[k]} \geq \sum_{j=1}^{n}\left\{a_{i j}^{[k]} p_{i}+\left(m_{i j}^{[k]}-z_{i j}^{[k]}\right) p_{i}\right\} \\
& \text { cost } \geq \text { price. }
\end{aligned}
$$

On the other side, it follows the price system subject to the nonzero excess profit condition:

Here, the wage rate of country $k$ is denoted by $w^{[k]}$.

As we have learned in the above, it is important to know that we cannot actually regard the domestic production system as the so-called independent system without taking into account any inter-country transactions, i.e., imports and exports. Therefore, the statistical bureau practically is providing us with the next three types of input-output tables (Director-General for Policy Planning 2016):

- $\quad$ Type $[I-A]^{-1}$

The construction of input-output table $A$ is based on the assumption of competitive imports. In this table, domestic and imported products are viewed neutrally and no distinction is drawn between them.

- $\quad$ Type $[I-[I-M] A]^{-1}$

Construction of the import coefficient matrix $M$ entails the removal of imported products from the above described competitive table $A$. This is based on the common ratio of the imported product to the total input among all of the products. All of the export outputs are assumed to be domestic products.

- Type $\left[I-A_{D}\right]^{-1}$

Based on the assumption of non-competitive imports, the actually detected ratio of the imported products to the total input of each industry can be calculated. 
Subsequently, a non-competitive table $A_{D}$ was constructed according to the extent of our knowledge.

In the following, we give a sight of the landscape of the actual traditional inputoutput table of 37 sectors classification in Japan in 2011. In Fig. 12, the axes perpendicular to the traditional input plane is limited to the non-negative numbers. This is one of the differences from the make minus use table. On the other hand, Fig. 13 shows the density distribution of the input coefficients of the same table. The scale of the vertical axis is measured in logarithm. The actual distribution of inputs of the sectors, at the first glance, seems randomly distributed. However, the author examined that this distribution did not necessarily become a random distribution. According to the random matrix theory, we will find some principal modes outside the estimated random distribution of eigen modes of the production system. This analysis was achieved in Aruka (2017) and elsewhere. In this article, we focus on another property of a network structure of the inter-country production system.

\subsection{Dual linear programmings of production and consumption in case of the international trade of the intermediate goods}

The above formulation never contains any selection process of international transaction of intermediate goods (industries) between countries. It could no longer stand the world system of international trade. We must move to a new augmented profile to embrace all the interaction of import and export between countries. We then construct a new array, i.e., commodities matrix $B$. The matrix is "arrayed" by a specific rule taking into account the mutual interaction of productive relationship between countries by the international trade.

The mutual interaction of multiple countries and many industries will generate a more complicated network difficult to grasp a whole relation. To avoid difficulties of new notations, it seems easily understandable to employ a numerical example to present how to construct the competitive process of international transaction of intermediate goods between countries. This operation will suggest the introduction

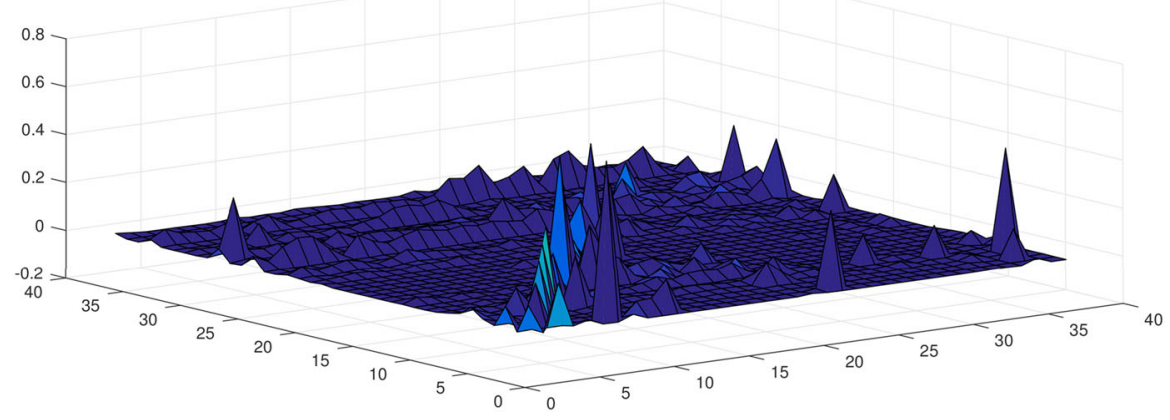

Fig. 12 Input-output table of 37 sectors in 2011, Japan 


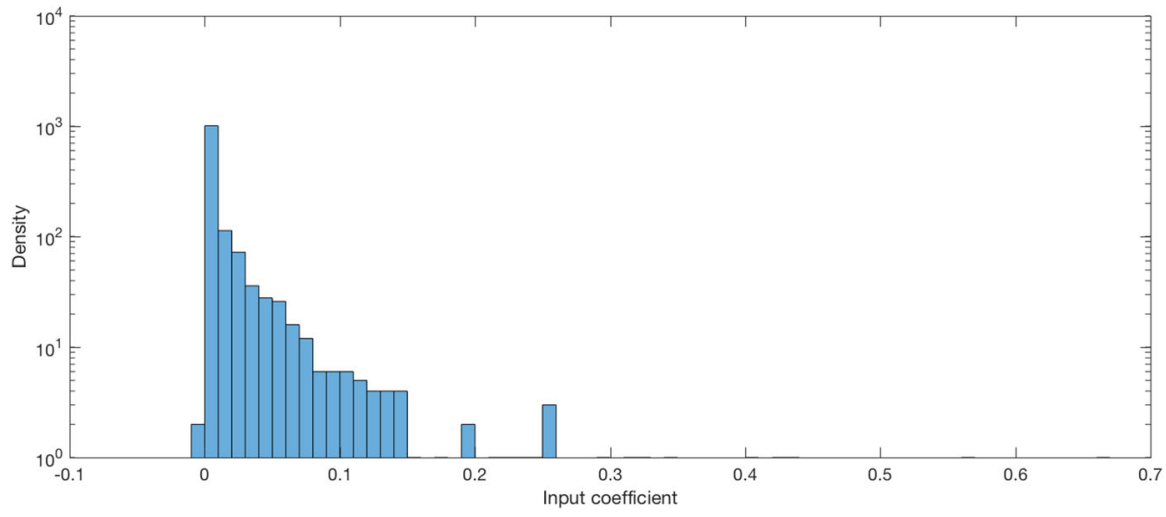

Fig. 13 Density distribution of the input coefficients of the same table in 2011

of the free trade system to all the inter-regional system. We, only for convenience of illustration, take the smallest case of 3 industries and the 2 countries, although our simulation refers to a more general case of the 3 countries -3 industries case later.

\subsubsection{The commodity matrix of 2 countries by 2 industries case}

We assume the make minus use table of 2 countries and 2 intermediate goods as follows (Tables 8, 9):

Given the above tables, we incorporate some slack variable to join two countries production systems and then construct the commodities space by the commodities matrix $B$ as well as the activity variables $y$ in the following manner (Table 10):

We thus specified the labels of the activities by the next rules to Country 1 in the smallest economy of the world production system containing the international trade. It then follows our optimization problem of the world production system.

On the other hand, the present example gives the commodities matrix $B$ being generated by taking into account slack variables. The next $B$ will be of the sparse form:

Table 8 Table of Country 1

\begin{tabular}{|c|c|c|c|c|c|}
\hline \multirow{2}{*}{$\begin{array}{l}\text { Country } 1 \\
\text { Limited trade }\end{array}$} & \multicolumn{2}{|c|}{ Country 1 infrastructure } & \multicolumn{2}{|c|}{ Net export from Country 1 to 2} & \multirow{2}{*}{$\begin{array}{l}\text { Country } 1 \\
\text { Consumption }\end{array}$} \\
\hline & Industry 1 & Industry 2 & Industry 1 & Industry 2 & \\
\hline Industry 1 & 25 & -12 & -3 & 0 & -10 \\
\hline Industry 2 & -10 & 25 & 0 & -5 & -10 \\
\hline Labour & -30 & -18 & 0 & 0 & 0 \\
\hline
\end{tabular}


Table 9 Table of Country 2

\begin{tabular}{|c|c|c|c|c|c|}
\hline \multirow{2}{*}{$\begin{array}{l}\text { Country } 2 \\
\text { Limited trade }\end{array}$} & \multicolumn{2}{|c|}{ Net export from Country 2 to 1} & \multicolumn{2}{|c|}{ Country 2 infrastructure } & \multirow{2}{*}{$\begin{array}{l}\text { Country } 2 \\
\text { Consumption }\end{array}$} \\
\hline & Industry 1 & Industry 2 & Industry 1 & Industry 2 & \\
\hline Industry 1 & 3 & 0 & 17 & -10 & -10 \\
\hline Industry 2 & 0 & 5 & -15 & 20 & -10 \\
\hline Labour & 0 & 0 & 0 & -12 & -1 \\
\hline
\end{tabular}

Table 10 Corresponding activity levels of Country 1 in the smallest international economy

\begin{tabular}{|c|c|c|c|c|c|c|}
\hline \multirow[t]{2}{*}{ Country 1} & \multicolumn{2}{|c|}{ Country 1 infrastructure } & \multicolumn{2}{|c|}{ Net export from Country 1 to 2} & \multirow{2}{*}{$\begin{array}{l}\text { Consumption } \\
\text { Consumption }\end{array}$} & \multirow{2}{*}{$\begin{array}{l}\text { Slack variable } \\
S\end{array}$} \\
\hline & Industry 1 & Industry 2 & Industry 1 & Industry 2 & & \\
\hline Industry 1 & $b_{11}$ & $b_{12}$ & $b_{13}$ & $b_{14}$ & $b_{15}$ & $b_{16}$ \\
\hline Industry 1 & $y_{11}$ & $y_{12}$ & $y_{13}$ & $y_{14}$ & $y_{15}$ & $y_{16}$ \\
\hline
\end{tabular}

$$
B=\left(\begin{array}{cccccccccccc}
25 & -12 & -3 & 0 & -10 & 0 & 0 & 0 & 0 & 0 & 0 & 0 \\
-10 & 25 & 0 & -5 & -10 & 0 & 0 & 0 & 0 & 0 & 0 & 0 \\
-30 & -18 & 0 & 0 & 0 & 0 & 0 & 0 & 0 & 0 & 0 & 0 \\
0 & 0 & 0 & 0 & 0 & 0 & 3 & 0 & 17 & -10 & -10 & 0 \\
0 & 0 & 0 & 0 & 0 & 0 & 0 & 5 & -15 & 20 & -10 & 0 \\
0 & 0 & 0 & 0 & 0 & 0 & 0 & 0 & -2 & -71 & 0 & 0 \\
0 & 0 & -3 & 0 & 0 & 0 & 3 & 0 & 0 & 0 & 0 & 0 \\
0 & 0 & 0 & -5 & 0 & 0 & 0 & 5 & 0 & 0 & 0 & 0 \\
0 & 0 & 0 & 0 & 0 & 1 & 0 & 0 & 0 & 0 & 0 & 0 \\
0 & 0 & 0 & 0 & 0 & 0 & 0 & 0 & 0 & 0 & 0 & 1
\end{array}\right) .
$$

The activities $y$ corresponding to the $B$ as well as the boundary condition on $y$ will be given as follows: 


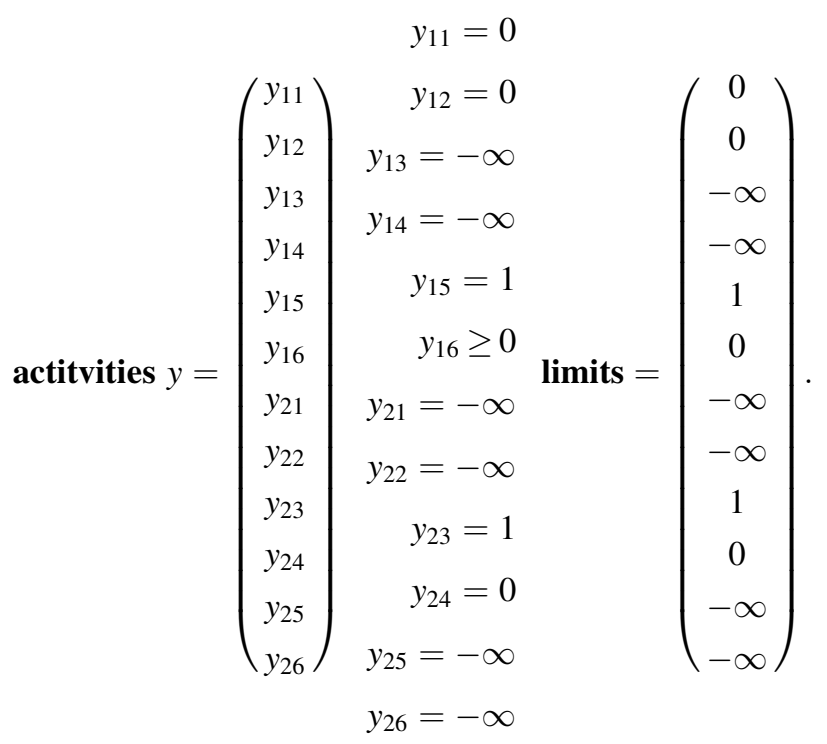

In addition, we note the boundary conditions on the activities $y$ by limits in the above relations.

Finally, we specify the resources. The production system requires the primary resources. In our example, just the labour is used differently from country to country.

$$
\text { resources } l=\left(\begin{array}{c}
0 \\
0 \\
-48 \\
0 \\
0 \\
-82 \\
0 \\
0 \\
0 \\
0
\end{array}\right)
$$

$$
\text { objective function }=\sum_{i}^{12} c_{j} y_{i j} \quad \text { subject to } \mathbf{B} y \nsupseteq l .
$$

Hence, we can formulate the linear programming of the world production system internally incorporated by the international trade. The prime problem is arranged Minimizing Problem in Mathematica formula.

It is noted that $¥$ implies the relations $y$ imposed on the above. In Mathematica formula, we summarize our optimization problem in the following manner: 
LinearProgramming [objective, commodities, resources, limits,

Method $\rightarrow$ InteriorPoint].

\subsubsection{The establishment of shadow prices including the wage rate}

It must be helpful to formulate the dual linear programming problem of the above prime problem:

$$
\text { objective function }=\sum_{i} p_{i} l_{i} \text { subject to } p \mathbf{B} \not \subset y
$$

DualLinearProgramming [objective, commodities, resources, limits,

$$
\text { Method } \rightarrow \text { InteriorPoint]. }
$$

In usual forms, it follows that

$$
\begin{aligned}
& p=\left(p_{11}, p_{12}, p_{13}, p_{14}, p_{15}, p_{21}, p_{22}, p_{23}, p_{24}, p_{25}\right) \\
& p=\left(p_{11}, p_{12}, p_{11}, p_{12}, w_{1}, p_{21}, p_{22}, p_{21}, p_{22}, w_{2}\right) .
\end{aligned}
$$

Here, $p$ is set as follows:

Here, it is also noted that the commodity price must be uniform both for the domestic price and the price for international transaction, that is

$$
\text { Domestic } \begin{aligned}
& p_{11}=p_{13} p_{21}=p_{23} \\
& p_{12}=p_{14} p_{22}=p_{24}
\end{aligned} \text { International. }
$$

The shadow price to support the optimization of the world production system is then established. It is important to know the shadow price of labour in the context of Shiozawa's international trade theory. Needless to say, the wage rate is just the shadow price of labour. In our dual programming, the wage rate must be different from country to country, on one hand. On the other hand, the prices of the commodities must be uniform in equilibrium each commodity all over the countries. As Shiozawa's theory confirmed, the driving force of the international trade is just the cost advantage due to the wage rate. Our dual programming has verified this fact by employing the idea of Nettleton (2011). The simulation has been achieved by rearranging the program of Nettleton (2011) on the Wolfram Demonstrations Project.

Finally, we mention the shadow prices of our numerical example of two countries by two industries case as a result of running the dual linear programming on the above table (Table 11):

It is apparent that the wage cost advantage is better in Country 2 than in Country 1, i.e., the wage rate of Country 2 is lower than it of Country 1 . Thus Country 1 was forced to give up the full operation of both industries. The table after deregulation of this case will be of the next form (Tables 12, 13):

Even in the case of the smallest world production system of the 2 countries by 2 industries, the simple idea of mutual specialization of industry composition between 
Table 11 Shadow prices of the 2 countries by 2 industries case

\begin{tabular}{lll}
\hline Countries & Commodities & Shadow prices \\
\hline Country 1 & Commodity 1 & 0.047 \\
Country 1 & Commodity 2 & 0.053 \\
Country 1 & Labour & 0.041 \\
Country 2 & Commodity 1 & 0.047 \\
Country 2 & Commodity 2 & 0.053 \\
Country 2 & Labour & 0.008 \\
\hline
\end{tabular}

Table 12 After deregulation table of Country 1

\begin{tabular}{|c|c|c|c|c|c|}
\hline \multirow{2}{*}{$\begin{array}{l}\text { Country } 1 \\
\text { Limited trade }\end{array}$} & \multicolumn{2}{|c|}{ Net export from Country 1 to 2} & \multicolumn{2}{|c|}{ Country 1 infrastructure } & \multirow{2}{*}{$\begin{array}{l}\text { Country } 1 \\
\text { Consumptior }\end{array}$} \\
\hline & Industry 1 & Industry 2 & Industry 1 & Industry 2 & \\
\hline Industry 1 & 0 & -32 & 43 & 0 & -11 \\
\hline Industry 2 & 0 & 67 & 0 & -56 & -11 \\
\hline Labour & 0 & -48 & 0 & 0 & 0 \\
\hline
\end{tabular}

Table 13 After deregulation table of Country 2

\begin{tabular}{|c|c|c|c|c|c|}
\hline \multirow{2}{*}{$\begin{array}{l}\text { Country } 2 \\
\text { Limited trade }\end{array}$} & \multicolumn{2}{|c|}{ Country 2 infrastructure } & \multicolumn{2}{|c|}{ Net export from Country 2 to 1} & \multirow{2}{*}{$\begin{array}{l}\text { Country } 2 \\
\text { Consumption }\end{array}$} \\
\hline & Industry 1 & Industry 2 & Industry 1 & Industry 2 & \\
\hline Industry 1 & -43 & 0 & 67 & -9 & -15 \\
\hline Industry 2 & 0 & 56 & -59 & 18 & -15 \\
\hline Labour & 0 & 0 & -8 & -65 & 0 \\
\hline
\end{tabular}

two countries does not hold. Thus, we will focus on a network analysis on the structural change after deregulation int the final subsection.

\subsubsection{The 3 countries by 3 industries case}

Finally, we focus on the change of the network structure of the inter-country systems before and after deregulation by means of Kirchhoff matrix as we already introduced. For a later reference, we show a numerical example randomly generated of the 3 countries by 3 industries case. We first specify the labels of the activities by the next rules to Country 1 (Tables 14,15 ).

As for the remaining countries in this inter-regional system Country 2 and 3, it then follows the result of the after deregulation. We first show the state transition of Country 2 (Table 16).

We finally show the state transition of Country 3 (Table 17). 


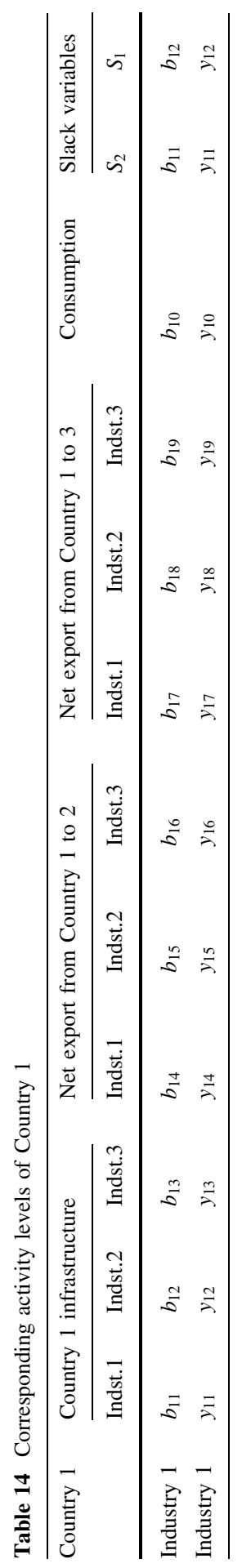




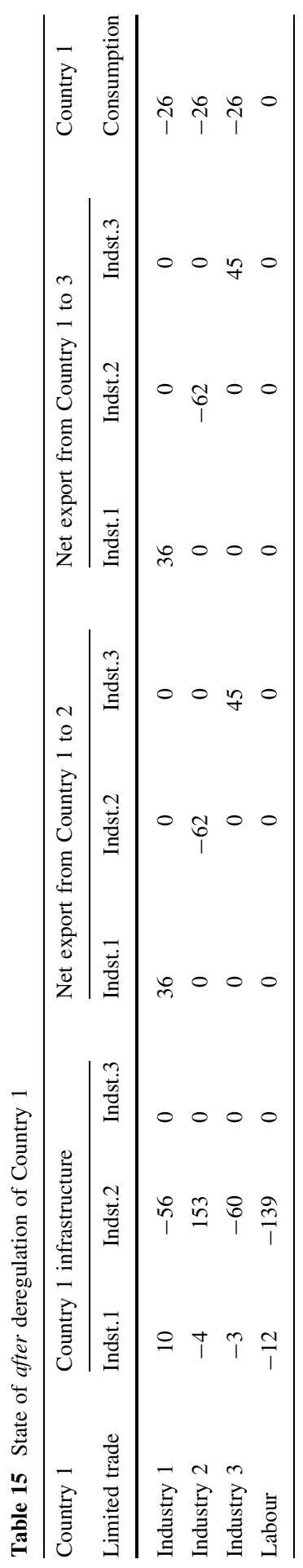




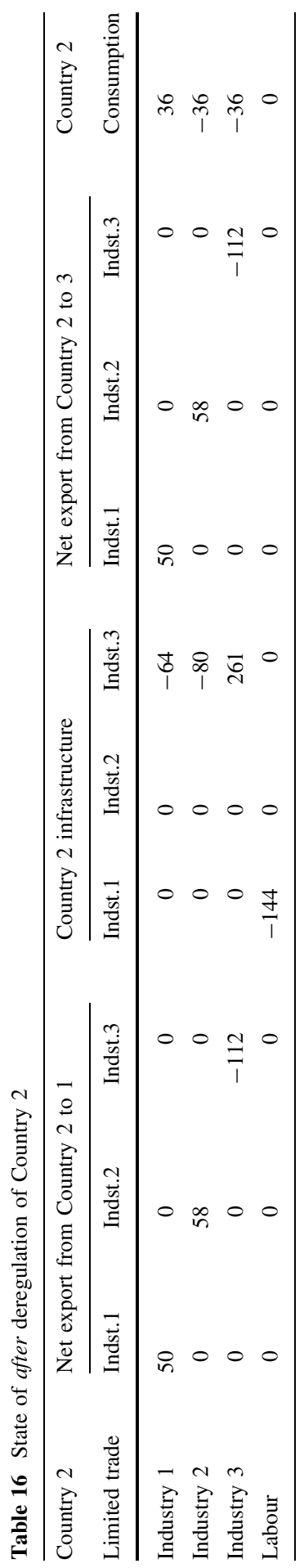




\subsection{Validity of the comparative advantage among countries mutually transacting}

Inspecting the items of net export among countries, the same industry of Country A gives the net export to Country B, vice versa. As shown in Tables 6 and 10, Industry 1 either in Country 1 or Country 3 can give the net export mutually, for instance. The international trade rather demonstrates the international transaction around the same intermediate good. The simulation result coincides with the empirical analysis. ${ }^{4}$

- The deregulation may generally expand the net outputs of the world. ${ }^{5}$

- However, the expansion of the international trades will not necessarily generate either the specialization of a particular industry or the balanced growth of interindustries.

- It may be rather observed that the productive network in some country is entirely destroyed to prevent from self-reproducing ever before.

Now, we characterize our simulation result on the network properties of before and after deregulation of the inter-country production and transaction system. In simulation, the numerical values are generated randomly. It then seems natural that the network structures from country to country are uniformly random. In this sense, each network structure seems similar among countries before deregulation. As the world production system moves to deregulation, however, we will see a drastic breakdown of egalitarian network structures among countries. We give a simulation result in the case of 5 countries.

\subsubsection{The transition of the landscape before and after deregulation}

First, we see the transition of the landscape of the use minus make table. Then we see the drastic change of the network structure among countries (Figs. 14, 15, 16, 17, 18, 19).

\subsubsection{The transition of the Kirchhoff diagram before and after deregulation}

In turn, we depict the change of the network structure by Kirchhoff diagram, as we already illustrated. This directed diagram can demonstrate the importance of the inter-industrial relationship explicitly. The thickness of the directed arrow represents the weight of input inwards the targeted nodes (industries). In our numerical example of 3 countries case, it follows the next transition of network structure.

\footnotetext{
4 As for the empirical econophysics verification, see Ikeda (2016):

5 It is apparent, because deregulation implies maximizing the total net output common to all the participating inter-country systems. Also see an example of the simulation by Nettleton (2011).
} 


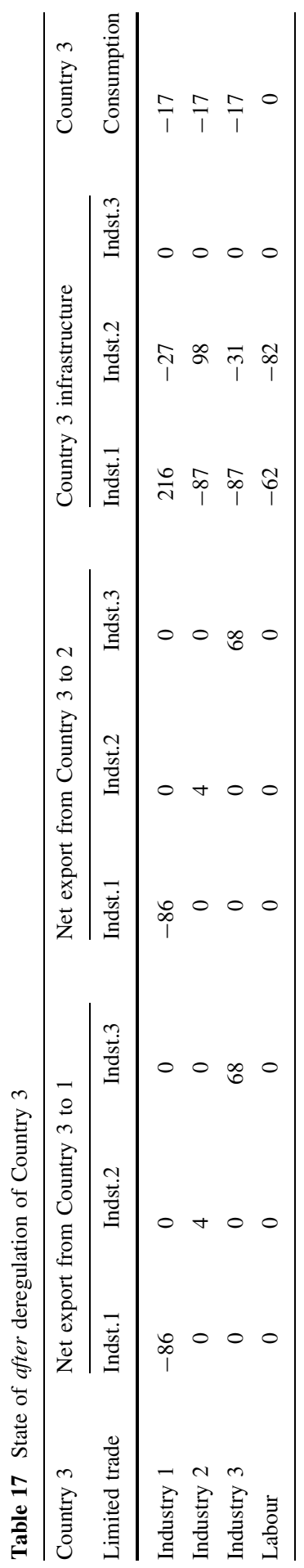



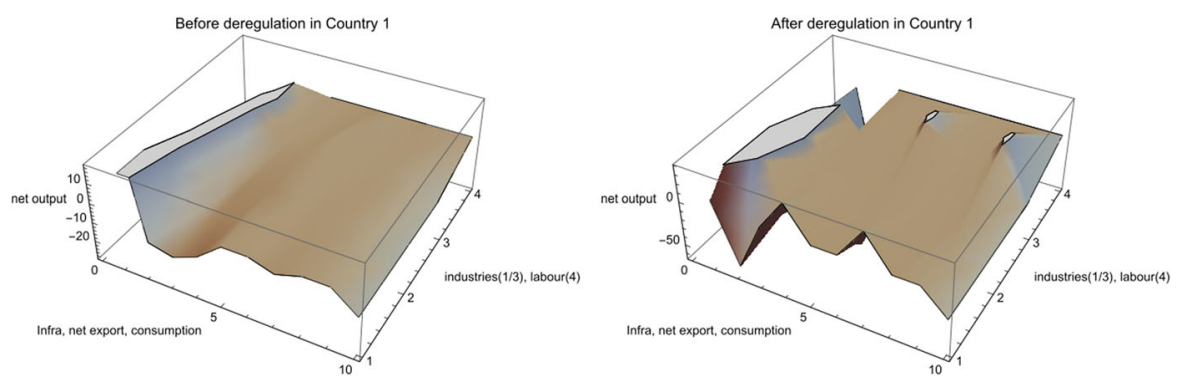

Fig. 14 All in one of the landscape of the smallest international economy
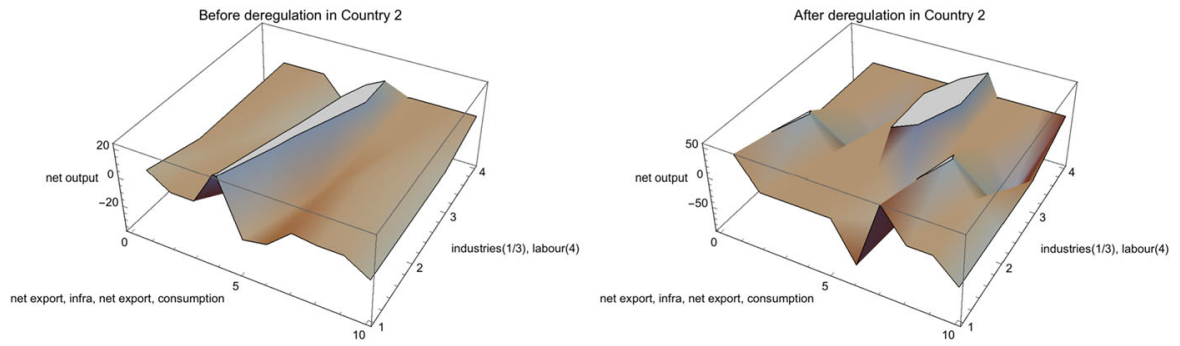

Fig. 15 Tansition of the landscape of the smallest international economy before and after deregulation in Country 2
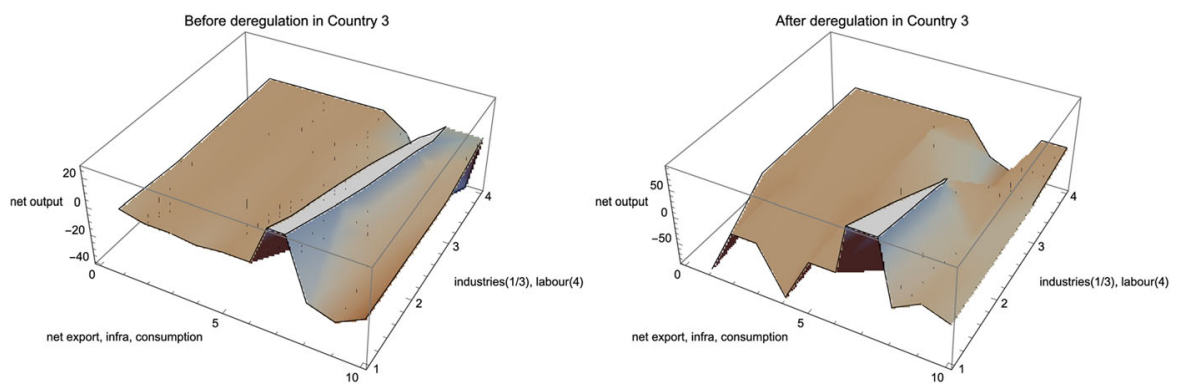

Fig. 16 Transition of the landscape of the smallest international economy before and after deregulation in Country 3
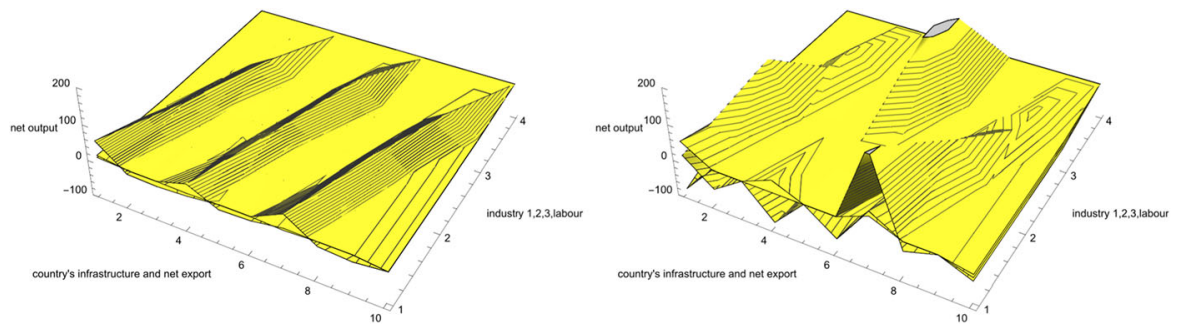

Fig. 17 All in one of the landscape of the smallest international economy 

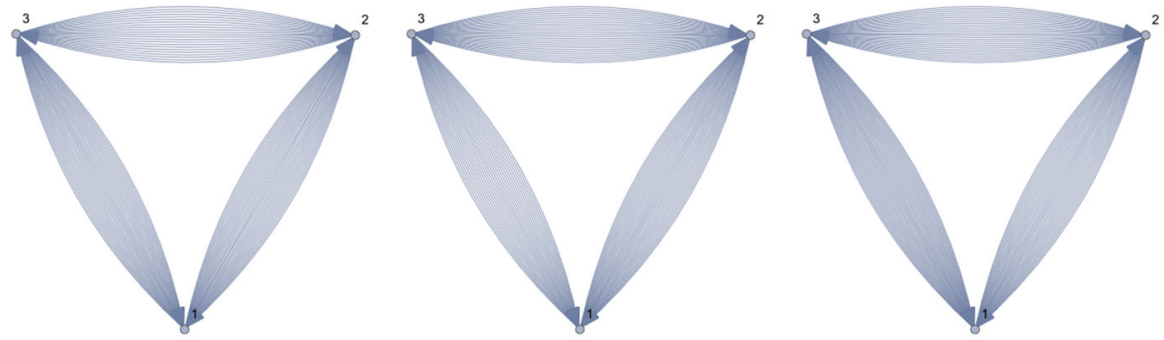

Fig. 18 Kirchhoff diagrams of the smallest international economy before deregulation
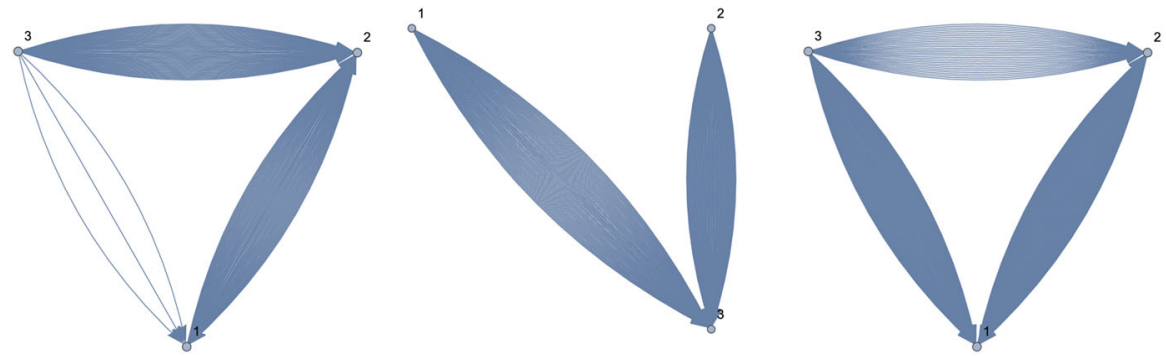

Fig. 19 Kirchhoff diagrams of the smallest international economy after deregulation

\section{Concluding remarks}

The economy essentially is sustained periodically through mediating industries (intermediate commodities), which is preparing for the next year's growth. In this process, on the other hand, the international trade must play a decisive role to reconnect the inter-industrial activities. The networked production and the international trade are then the cooperative factors for the growing/decaying process of the national/regional economy. In this point of view, Ikeda (2016) seems smartly navigating an empirically based analysis of the worldwide economy by employing the world input-output data and the international trade data. In Ikeda (2016), the fundamental set of the analysis for this purpose is neatly well defined in view of econophysics. The community structure of the system is interestingly driven according to the idea of the modularity benefit function, for instance. An undirected multiplex network may then be employed to detect the community structure in a time-dependent network.

To deal with the dynamics of the world economy and to explore the structural controllability of the world system, it is also pointed out by Ikeda (2016) that the idea of "driver nodes" (partially and globally) is "identified by the maximum matching in the bipartite representation of the network" due to Newman (2006). Here an integer linear programming is applied.

It is quite interesting to learn the driven propositions in this paper. Although there are many interesting findings, among them, the next two findings of Ikeda (2016) are very interesting: 
1. "[T]he increase of the number of driver nodes during economic crisis is explained qualitatively by the heterogeneity in terms of degree distribution."

2. These community structure means that international trade is actively transacted among same or similar industry sectors.

In view of the proposition (2), the traditional international trade doctrine should be reconsidered. In fact, the free trade will not give rise some industrial specialization between countries. A new approach seems much more excellent in examining the effects of the international trade. However, Ikeda (2016) does not necessarily fetch the true interaction of inter-country interaction through the import and export, because the idea of relative prices and distributive factors like wage rate are not explicitly argued similarly as in econophysics analysis. In particular, the wage rate must play a decisive role for the international trade. If the wage rate comparison should be explicitly taken into account, the perspective of their paper could be much improved. We wished to show their point of view here.

The effect of the international trade is decisively different from a merger of any independent units. However, an analysis of the world production system requires a more complicated idea of production system. A possibility set of production composed of two countries may be generated as a zonotope of two facet of country's production. The sphere the activity analysis targets is merely a part of the zonotope set. Thus, according to Shiozawa (2016), we employ a new tropical geometry and were successful to introduce a hyperplane of wage-price coordinates, and argued a price competition in a general case of the international trade of multiple intermediate commodities between multiple countries. Hence, Shiozawa was successful to demonstrate properly that any idea of industry specialization in country is irrelevant to confirm any cost advantage of the international trade. The cost advantage holds without any idea of optimization. We, however, examined the effects to introduce the framework of free trade, i.e., deregulation each country. According to a network analysis, the introduction of free trade suggests a drastic change of industrial networks each country. The result may be disastrous for employment of some country.

Open Access This article is distributed under the terms of the Creative Commons Attribution 4.0 International License (http://creativecommons.org/licenses/by/4.0/), which permits unrestricted use, distribution, and reproduction in any medium, provided you give appropriate credit to the original author(s) and the source, provide a link to the Creative Commons license, and indicate if changes were made.

\section{References}

Aruka Y (2017) Chapter 2: Systemic risks in the evolution of complex social systems. In: Aruka Y, Kirman A (eds) Economic foundations for social complexity science: theory, sentiments, and empirical laws. Springer, Berlin

Brechtefeld F (2012) Efficient total production through specialization. Wolfram Demonstrations Project Director-General for Policy Planning (Statistical Standards 2011) (2016) Input-output tables for Japan. In: Input-output tables for Japan. Ministry of Internal Affairs and Communications, Japan

Dosi G, Grazzi M, Marrengo L, Settepanella S (2016) Production theory: accounting for firm heterogeneity and technical change. J Ind Econ 64(4):875-907 
Fujimoto T (2007) Architecture-based comparative advantage-a design information view of manufacturing. Evolut Inst Econ Rev 4(1):55-112

Fujimoto T, Shiozawa Y (2012) Inter and intra company competition in the age of global competition: a micro and macro interpretation of Ricardian trade theory. Evolut Inst Econ Rev 8(2):193-231

Hildenbrand W (1981) Short-run production functions based on microdata. Econometrica 49(5):1095-1125

Ikeda Y et al (2016) Econophysics point of view of trade liberalization: community dynamics, synchronization, and controllability as example of collective motions. RIETI Discuss Pap Ser 16(E26): 1-35

Jones RW (1961) Comparative advantage and the theory of tariffs: a multi-country, multi-commodity model. Rev Econ Stud 28:161-175

Maurer SB (1976) Matrix generalizations of some theorems on trees, cycles and cocycles in graphs. SIAM J Appl Math 30(1):143-148

Nettleton SJ (2011) Computable general equilibrium (CGE) of multiregion input-output model. Wolfram Demonstrations Project

Newman MEJ (2006) Finding community structure in networks using the eigenvectors of matrices. Phys Rev E 74:036104-1-036104-22

Raa T (2006) The economics of input-output analysis. Cambridge University Press, Cambridge

Shiozawa Y (2007) A new construction of Ricardian trade theory-a many-country, many-commodity case with intermediate goods and choice of production techniques. Evolut Inst Econ Rev 3(2): $141-187$

Shiozawa Y (2016) International trade theory and exotic algebras. Evolut Inst Econ Rev 12(1):177-212

Shiozawa Y (2017) Chapter 1: The new theory of international values: an overview. In: Shiozawa Y, Oka T, Tabuchi T (eds) A new construction of Ricardian theory of international values: analytical and historical approach. Springer, Berlin, pp 3-73

Shiozawa Y, Oka T, Tabuchi T (eds) (2017) A new construction of Ricardian theory of international values: analytical and historical approach. Springer Nature, Berlin

Wikipedia (2017) Kirchhoff's theorem. https://en.wikipedia.org/wiki/Kirchhoff\%27s_theorem. Accessed 15 Apr 2017

Wolfram Language and System Documentation Center (2015) Kirchhoff matrix. Wolfram Language and System Documentation Center, Champaign 